\title{
Yoga bei Hitzegefühl/Überhitzung
}

Liebe Patientin, lieber Patient,

der menschliche Körper kann seine Temperatur für gewöhnlich selbst regulieren. Die natürliche Körpertemperatur, die wir über die Haut messen können, schwankt im Regelfall zwischen 36 und $37^{\circ}$ Celsius. Steigt die Körpertemperatur ohne Infekt oder Allergie an, liegt dies meist an drei Möglichkeiten: der Stoffwechsel der inneren Organe ist angeregt (z.B. durch Fasten oder Stress), wir betreiben gerade aktive Muskelarbeit oder die Hitzequelle liegt außerhalb des Körpers (z. B. übermäßige Hitzezufuhr durch intensive Sonneneinstrahlung). Die steigende Temperatur unseres Organismus kann im Normalfall durch körpereigene Mechanismen reguliert werden.

Einer dieser Mechanismen ist uns allen bekannt: Wir schwitzen. Der Schweiß verdunstet auf der Haut und regelt auf diese Weise den Temperaturausgleich. Eine weitere Möglichkeit ist es, die Wärme über die Haut und die Atmung an die uns umgebende Luft abzugeben. Die Temperaturregulation geschieht auch im Inneren unseres Körpers, in den Blutbahnen. Wenn sich unsere Blutgefäße weiten, gibt der Körper Wärme ab.

Wenn die Mechanismen zur Regulierung der eigenen Körperwärme nicht ausreichen, überhitzt unser System. Die Temperatur des gesamten Organismus steigt als reaktiver Funktionsablauf, und es kommt zu einer vegetativen Umschaltung. Durch diese Gesamtbeeinflussung wird uns heiß mit z. B. Herzrasen und/oder Schwindel.

In der Yogatherapie wird zur Unterstützung der Regulierung der Körpertemperatur die Körperhaltung Yoga Mudra empfohlen.

Yoga Mudra (siehe Abb. 1): Hierzu kniet man mit ca. faustbreitem Abstand zwischen den Knien und 2-5 daumenbreitem Abstand zwischen den großen Zehen und lässt sich mit dem Gesäß langsam nieder, wobei man sich nicht auf die Fersen setzt, sondern in die von ihnen gebildete Mulde.

Von dieser Stellung ausgehend beugt man sich so weit wie möglich nach vorne,

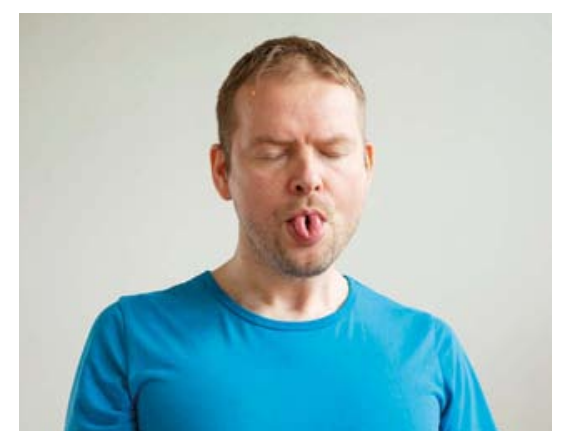

Abb. 2 Shitali Atmung. Quelle: Deutsche Akademie für traditionelles Yoga e. $V$.

sodass die Stirn den Boden berührt. Nach Möglichkeit soll das Gesäß in Berührung mit den Fersen bleiben. Die Arme werden nach vorne ausgestreckt, mit den Handflächen nach unten gerichtet, ohne angespannt oder überdehnt zu sein, so als ob man sich verbeugen würde. Die Konzentration ist auf die Mitte der Brust gerichtet, und die Atmung ruhig und entspannt, aber tief. Man hält diese Stellung so lange, bis man deutlich Erleichterung empfindet.

Sollte das Yoga Mudra nicht ausreichen, gibt es zwei Atemtechniken, die kühlend auf den gesamten Organismus wirken. Die erstere wirkt etwas stärker, kann aber nur ausgeführt werden, wenn man seine Zunge rollen kann.

Shitali-Atmung (siehe Abb. 2): Bei dieser Methode atmet man langsam, tief und vollständig durch den Mund ein. Der Luftstrom strömt dabei durch das von der Zunge gebildete Röllchen. Ist die Lunge voll, kann man den Atem kurz anhalten.

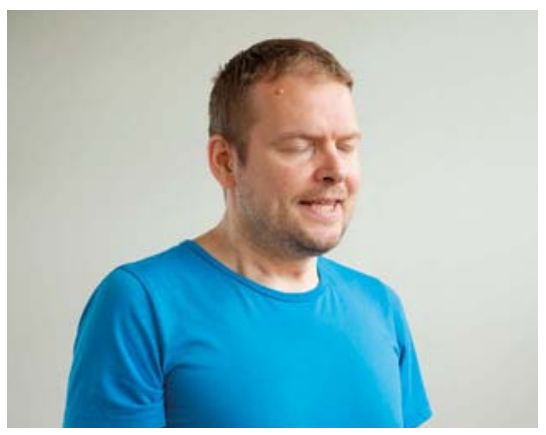

Abb. 3 Sitakari-Atmung. Quelle: Deutsche Akademie für traditionelles Yoga e. $V$.

Danach atmet man langsam durch die Nase aus. Diesen Vorgang wiederholt man ohne sich anzustrengen oder dass einem schwindelig wird, bis man abgekühlt ist. Sitakari-Atmung (siehe Abb. 3): Bei dieser Atmung stößt die Zunge von hinten an die Vorderzähne des Unterkiefers, die Zähne liegen aufeinander und die Luft strömt auch hierbei über die Zunge. Nach kurzem Anhalten der Atmung bei vollen Lungen atmet man wieder über die Nase aus.

Dieser Artikel ist online zu finden: http://dx.doi.org/10.1055/a-1146-5673

\section{Mit den besten Grüßen überreicht:}

Praxisstempel/Unterschrift 